\title{
ERJ
}

Engineering Research Journal

Faculty of Engineering

Menoufia University

\section{Friction Stir Spot Welding - A validation Study for Optimal Welding Parameters of Aluminum Alloy 6061}

\author{
Mohammed A. Tashkandi \\ Department of Mechanical Engineering, Northern Border University, Saudi Arabia \\ Email: mtashkandi@nbu.edu.sa
}

\begin{abstract}
:
Friction stir spot welding is a unique solid-state process for joining different metallic components in many applications such as automotive industry. It is very widely used and being considered as a superior alternative to conventional joining methods. The welding process parameters include the tool rotational speed, pin length, shoulder width and dwell time. Optimum process parameters where identified in prior investigations that produced the highest joint strength for this type pf alloys. This paper is a trial to validate these results and explain the high strength of the welded joint through microstructural investigations. Optical microscopy, scanning electron microscopy and Vicker's microhardness tests were used to analyze the welded joint. The investigation validated the optimum process conditions in microstructural and hardness variations across the different zones of the welded joint.
\end{abstract}

Keywords: Friction Stir Spot Welding, Welding Process Parameters, Welding Defects, Microstructure.

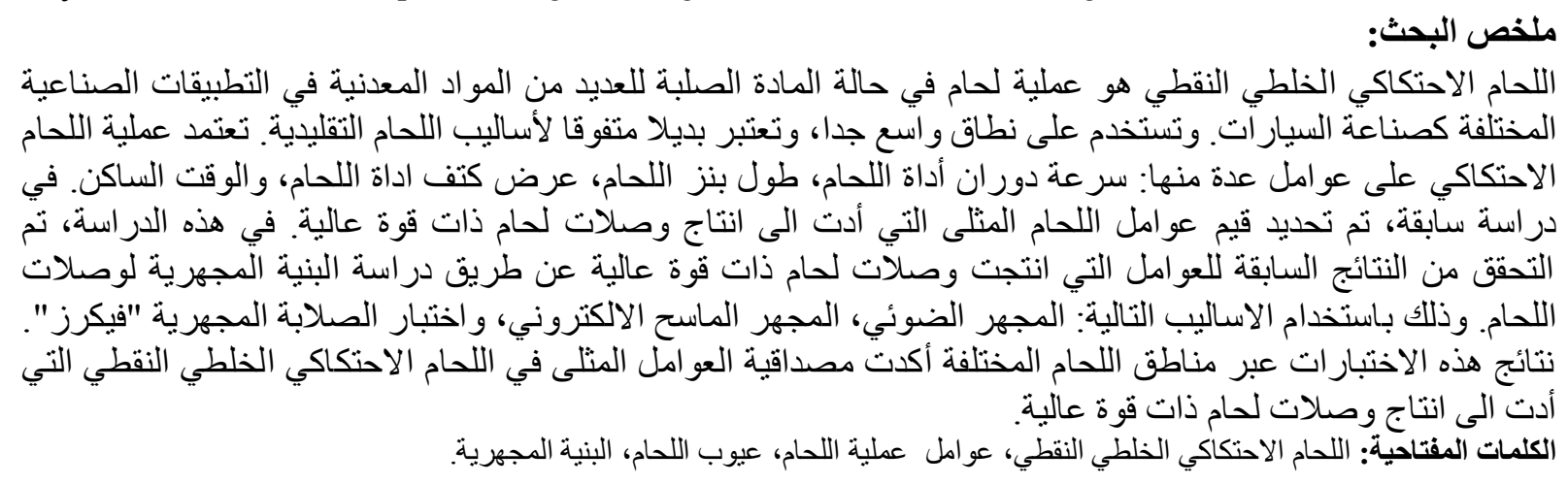

\section{Introduction}

When it comes to joining materials or machine components that requires a spot joining, many techniques exist. Conventional methods include Electric resistance spot welding, riveting, and using bolts and nuts. Electrical resistance spot welding (ERSW) is widely used in many applications. The issue with ERSW is the formation of an intermetallic layer that has a significant thickness and can hinder the joint performance [1]. Also, ERSW requires a huge amount of energy, the material structure upon welding changes and hence the material's mechanical properties [2]. On the other hand, friction stir spot welding is a solid-state welding technique that involves joining two different parts without allowing the material to melt to keep its mechanical properties.
Friction stir welding (FSW) was invented back in 1995 [3], the welding process requires a welding tool rotating at a specific rotational speed; the tool moves across the parts to be welded and causes material stir and thus spot joining the materials. Friction stir spot welding (FSSW) is used to join sheets or materials that requires specific joining methods such as applications that require bolts and rivets. FSSW is a superior to all these conventional joining techniques because it is much faster, reduces stress concentrations and preserves material properties since the material are being joined by plastic flow [4]. Some of the additional advantages of friction welding are: less energy consumption, more economical and also more environmentally friendly as compared to conventional welding techniques $[5,6]$.

Previously [7], an article investigating the welding parameters of FSSW for joining Al6061 sheets and 
their effect on the lap-shear fracture load of the joints was published. The welding parameters are rotational speed, shoulder diameter, pin length and dwell time. In addition, a second article investigating the welding parameters of FSSW from an experimental design perspective utilizing Taguchi statistical analysis was also published [8]. Based on these studies, optimal FSSW parameters for 6061 aluminum alloy were identified. The optimal process parameters are the factors that were significant in the statistical analysis and predicted to produce the strongest joint. This paper is aimed at validating the results obtained in the previous studies $[7,8]$ by means of metallographic analysis as well as microhardness tests.

The welding joint produced by FSSW has four distinct regions. These are the base metal, heat affected zone, thermodynamically affected zone and stir zone. The base metal (BM) is the region of the material that is not affected by the thermal welding cycle. As a result, experiences no plastic deformation or changes in the mechanical and microstructural properties. The heat affected zone (HAZ) is identified as the region that is very close to the welding center and has modified microstructural and mechanical properties due to the welding thermal cycle. In addition, HAZ does not undergo any plastic deformation. The thermomechanical affected zone (TMAZ) lies even closer to the welding center, undergoes microstructural changes due to a moderate thermal cycle. In addition, the plastic deformation in the TMAZ region is moderate and no recrystallization occurs. Consequently, the grains are more elongated and more deformed as compared to those in the HAZ region. Depending on the alloy treatment, temperature recovery is predominant and alloy over-aging can occur. Identifying the TMAZ region is can be tricky; it cannot be easily identified except by a micrographical analysis coupled with a hardness test profile. Finally, the stir zone (SZ) contains material that had intense plastic deformation and significant microstructural modifications due to the high temperature-friction effect that was introduced via the welding tool. Such conditions promote dynamic morphological modifications and allow both the upper and lower material sheets to be stirred together until their boundaries become imperceptible. $[9,10]$

\section{Methodology}

The chemical composition of 6061 aluminum alloy in weight percent is shown in table 1 . The optimum welding parameters for joining Al6061 alloys using
FSSW according to the previous studies [7,8] are shown in Table 2. These parameters were considered as the optimum levels since they resulted in the highest lap-shear load before fracture and showed significance in the results of the statistical analysis. Three samples of under these optimum FSSW parameters were made and studied via different techniques.

Table 1: Chemical composition of Al6061 alloy [7].

\begin{tabular}{ccccccc}
$\mathrm{Si}$ & $\mathrm{Mg}$ & $\mathrm{Cu}$ & $\mathrm{Fe}$ & $\mathrm{Mn}$ & $\mathrm{Ti}$ & $\mathrm{Al}$ \\
0.75 & 0.9 & 0.5 & 0.5 & 0.15 & 0.05 & Rest \\
\hline
\end{tabular}

Table 2: FSSW optimum process parameters [8].

\begin{tabular}{ccccc}
\hline $\begin{array}{c}\text { Welding } \\
\text { parameter }\end{array}$ & $\begin{array}{c}\text { Tool } \\
\text { rotational } \\
\text { speed }\end{array}$ & $\begin{array}{c}\text { Pin } \\
\text { length }\end{array}$ & $\begin{array}{c}\text { Shoulder } \\
\text { width }\end{array}$ & $\begin{array}{c}\text { Dwell } \\
\text { time }\end{array}$ \\
\hline $\begin{array}{c}\text { Optimal } \\
\text { Value }\end{array}$ & $1120 \mathrm{rpm}$ & $4.5 \mathrm{~mm}$ & $15 \mathrm{~mm}$ & $35 \mathrm{~s}$ \\
\hline
\end{tabular}

Plates of aluminum alloy 6061 with thickness of 3 $\mathrm{mm}$ thick were used to fabricate the joint under the optimal conditions. As shown in Fig. 1, the sample geometry consists of two plates each $100 \mathrm{~mm}$ long and $30 \mathrm{~mm}$ wide. The sample overlap was $30 \mathrm{~mm}$ and the two plates were lap-welded by the FSSW process. The welding process was achieved by using a vertical milling machine, where the head of the machine was tilted with 0.5 degrees and a special fixture was fabricated to hold the plates and eliminate any vibrations.

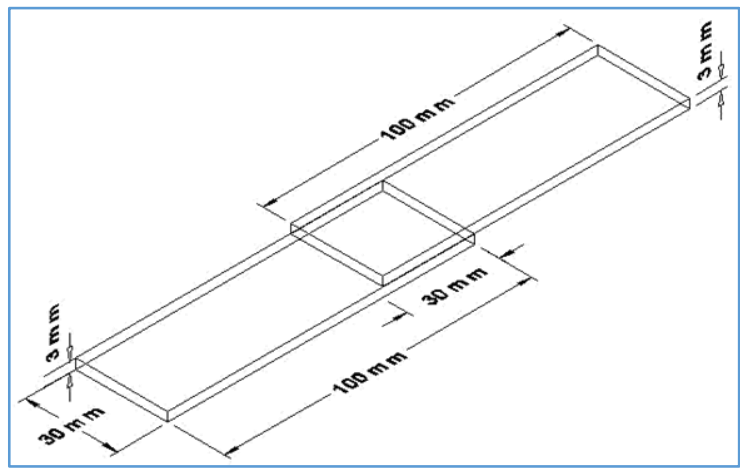

Fig. 1 Sample geometry for the welding process [7].

Three samples of the optimum FSSW parameters were made and studied. Surface morphology, grain structure and welding defects were investigated using Optical Microscopy (OM) and Scanning Electron Microscopy (SEM). Sample preparation for investigation involved cutting the welded joint by a precision cutting (model PICO 175) machine 
followed by polishing. Afterwards, the samples were etched with Killer's reagent for a duration of 10 s. Joint hardness was assessed by Vickers Microhardness test. The microhardness test was conducted as per the test HVS-1000, combined with a $200 \mathrm{~g}$ load for a duration of $10 \mathrm{~s}$.

\section{Results and Discussion}

Joints prepared by the FSSW process were examined using OM and SEM along the BM, the HAZ, the TMAZ, and the SZ. In addition, microhardness was measured within these regions in order to evaluate the microhardness of the welded joint.

\subsection{Optical Microscopy}

Typically, friction-welding processes such as FSW and FSSW show the same distinct five microstructural regions. These are the $\mathrm{BM}$, the HAZ, the TMAZ, the SZ and the Hook as shown in Fig.2. After welding the sheets according to the optimum welding parameters, cutting, polishing and etching, the welding cross-sections were examined. These cross-sections exhibited a bowl-shaped plug appearance; also known as a keyhole, due to the presence of the pin of the welding tool, which leaves this bowl-shaped vacancy in the welded sheets. This is also attributed to the fact that the optimum pin length was set to $4.5 \mathrm{~mm}$ which is the entire thickness of the upper sheet and half the thickness of the of the lower sheet. The macrostructure of the FSSW specimens was observed using a digital camera. In order to study various weld regions, the cross-section was divided into the regions shown in Fig. 3, according to the grained feature of the welds. These are namely: BM, HAZ, TMAZ and SZ. Note the absence of the
Hook in the welding joint except for a brief hint on the right side of the welded joint.

Optical micrographs of the various regions shown earlier in Fig. 3, are also shown in Figs. 4 and 5. Comparing the $\mathrm{BM}$ to the various weld regions outlined some differences in the microstructure that are due to the differences in thermal cycle within these regions. The grain structure seemed refined and equiaxed in the SZ as compared to BM. This can be attributed to the heavy material flow and the plastic deformation in the SZ, thus the refined and equiaxed grain structure that may enhance the strength of the material. In contrast, the TMAZ region seemed to have a less deformed structure than the SZ region because of the lower heat generation, which was not sufficient to refine the grain structure. Finally, the HAZ showed a grain structure that was almost similar to the BM and seemed that it was not affected by the heat.

Except for the refined and equiaxed grains in the $\mathrm{SZ}$, there is no clear difference in the microstructure of the different zones from OM after FSSW process of $6061 \mathrm{Al}$ alloy in the present research work. The resulting microstructure of the SZ consisted of grains, which were roughly equiaxed and often an order of magnitude smaller than the grains in the $\mathrm{BM}$. In the SZ, temperature reaches approximately $80 \%$ of the fusion temperature of the material; hence, only plasticization occurs. This could be explained due to the optimum welding parameters used for these samples [8]. Also, according to the previous work [7]; joints that had these optimum welding parameters had the highest lap shear load. All these OM details and the absence of weld defects such as chips and hooks may have promoted the consistency of the mechanical properties along the welded material to a great extent and hence explain the high lap-shear strength of the joint.

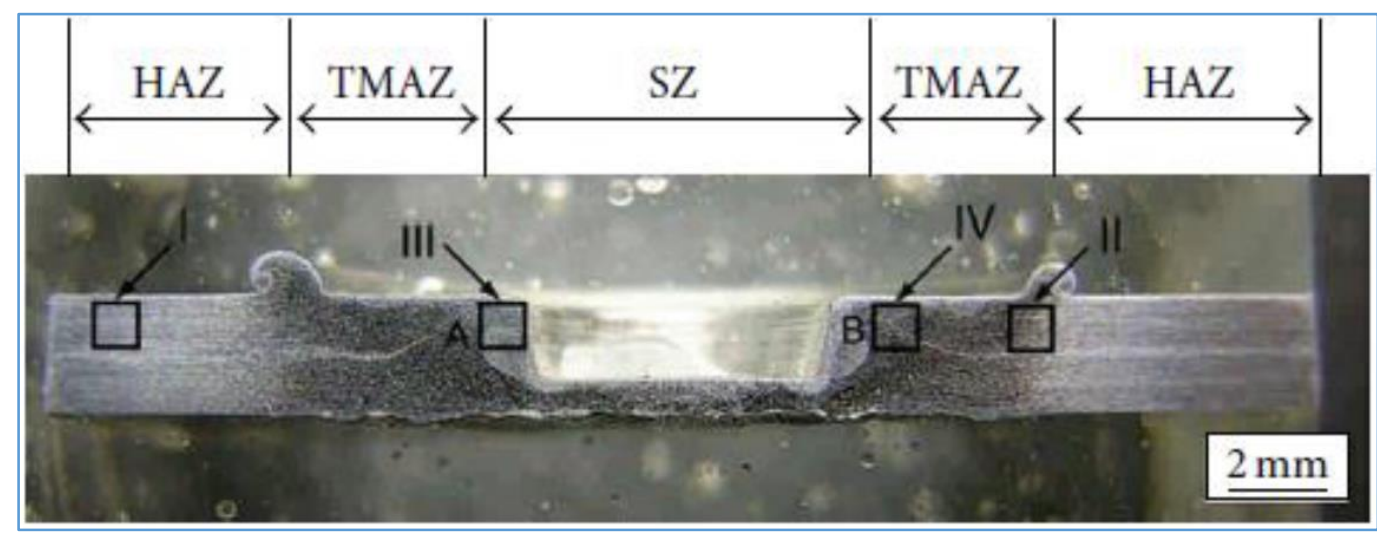

Fig. 2 Typical FSSW welding zones. [11] 


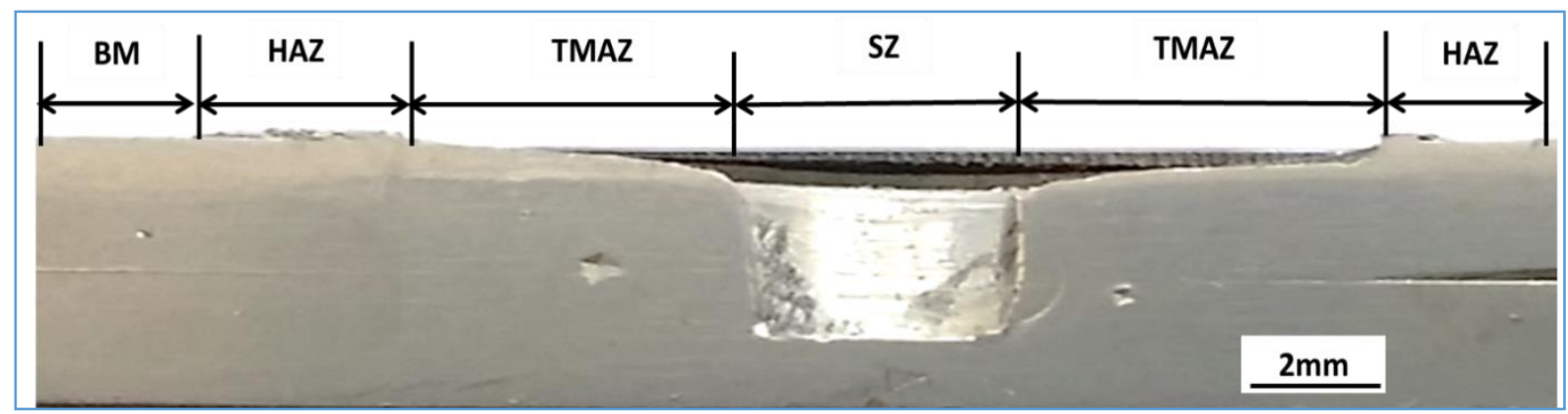

Fig. 3 Macroscopic macrograph of the welded joint.

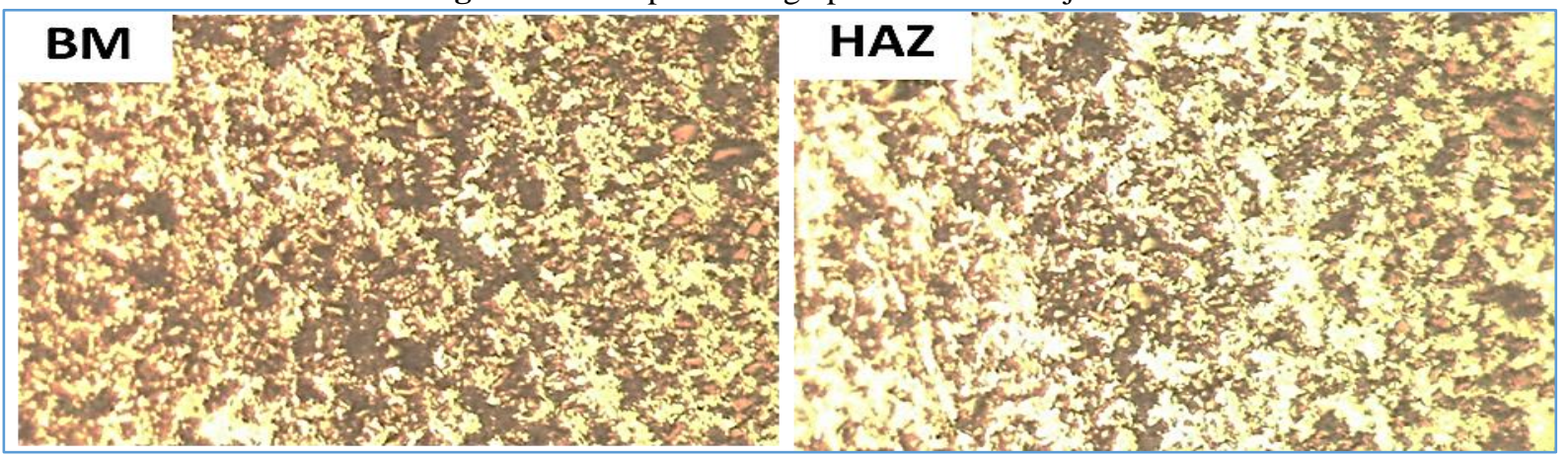

Fig. 4 Optical Microscopic micrographs showing the structure of the base metal (BM) and the heat affected zone (HAZ), 200X.

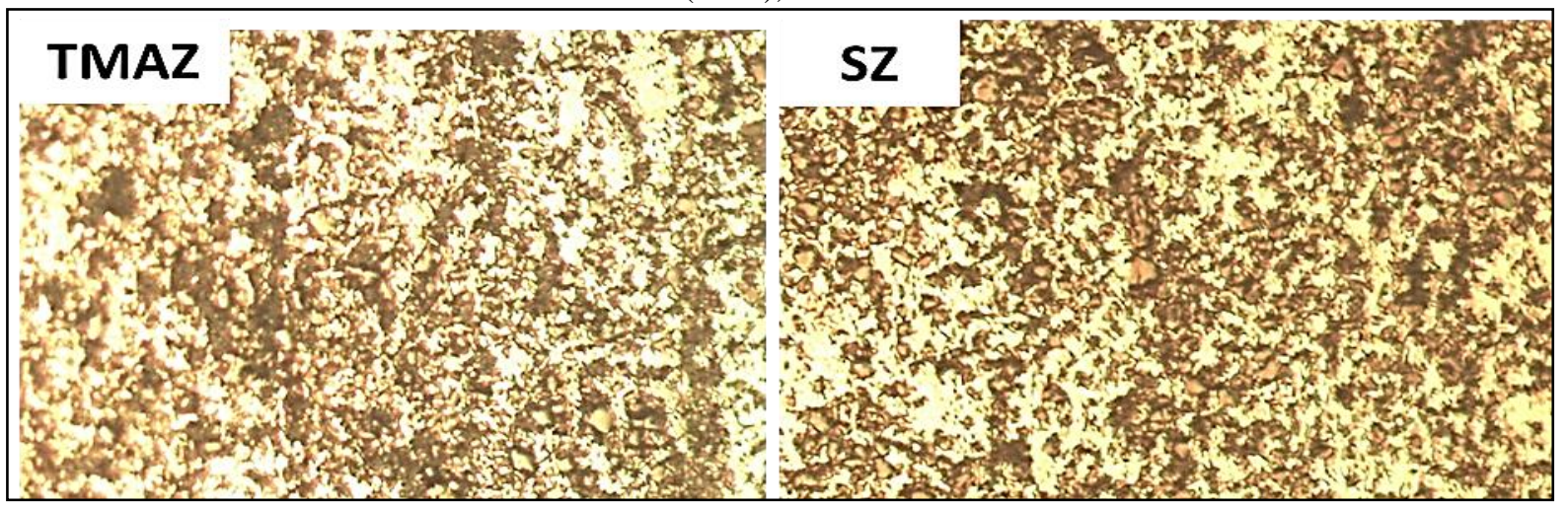

Fig. 5 Optical Microscopic micrographs showing the structure of the thermomechanical affected zone (TMAZ) and the stir zone (SZ), 200X.

\subsection{Scanning Electron Microscopy}

Figures 6 and 7 show SEM micrographs of both the $\mathrm{BM}$ and the SZ of the welded FSSW 6061Al alloy respectively. The stir zone SEM micrograph reveals fine equiaxed structure compared to the coarse grains of the BM. The SZ is a fully recrystallized region due to being in the immediate vicinity of the welding tool. The grains within the SZ are roughly fine and equiaxed and appear to be an order of magnitude smaller than the grains in the BM (or parent material). This due to the higher temperature and the severe plastic deformation within the SZ resulting in smaller grains in the microstructure. The next area being affected by the thermal cycle is the HAZ. It lies closer to the weld-center and the microstructure and/or the mechanical property within this region are altered due to the thermal cycle mentioned above. In addition, there is no plastic deformation in this region. The microstructure within the HAZ as shown in Figs. 8 and 9 seems to be similar to that of the base metal, as the grains look coarse. However, indications of some nucleation and ongoing recrystallizations were observed as tiny small white dots in the SEM micrographs. 


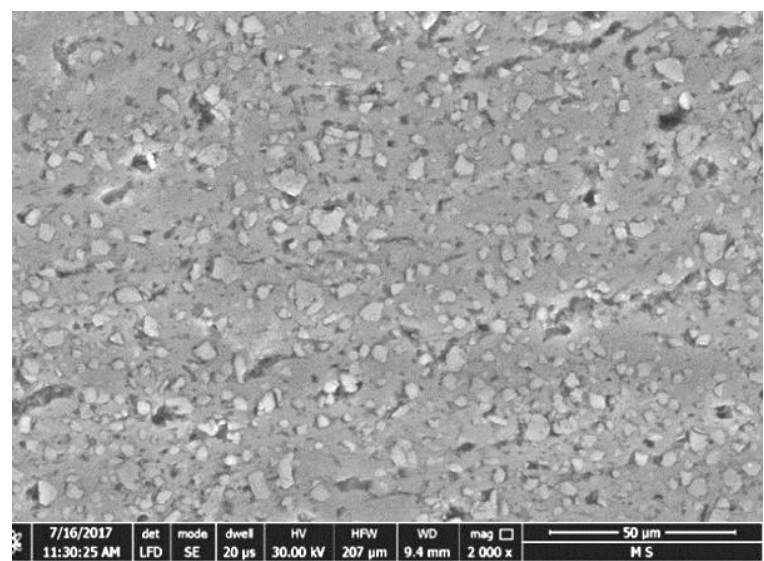

Fig. 6 SEM micrographs of (a) the BM.

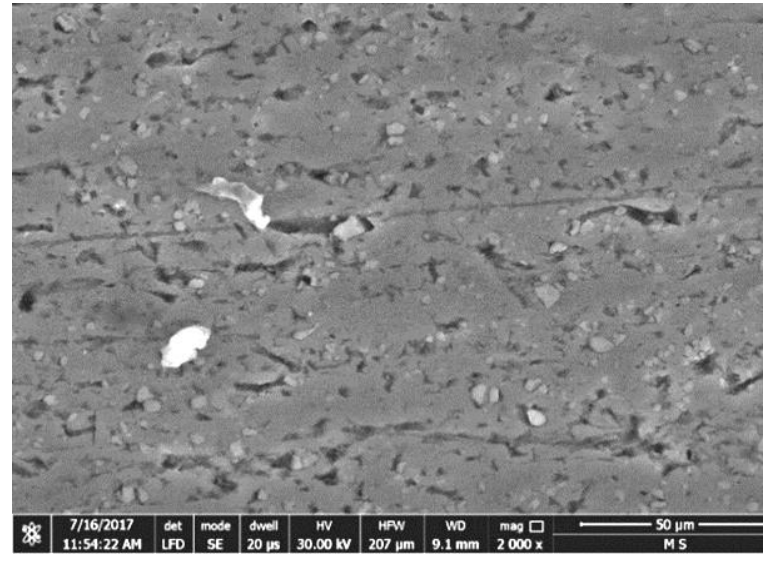

Fig. 7 SEM micrograph of the SZ.

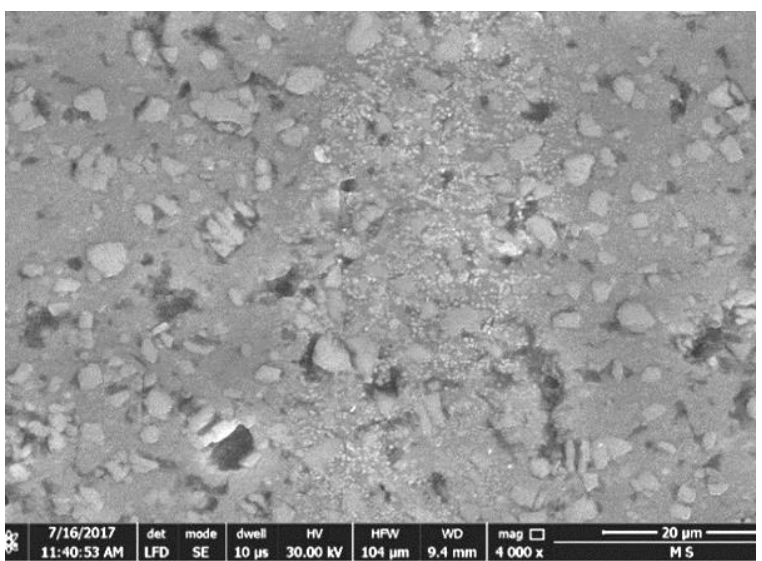

Fig. 8 SEM micrograph of the HAZ at a magnification of $4000 \mathrm{X}$.

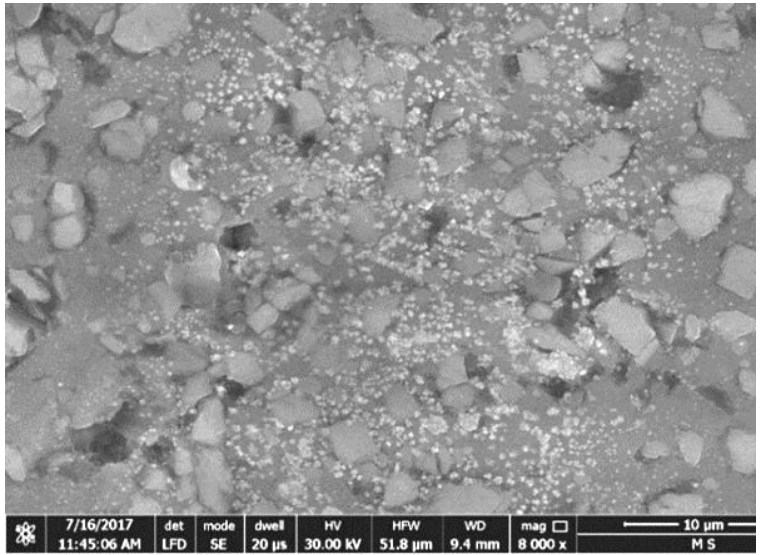

Fig. 9 SEM micrograph of the HAZ at a magnification of $8000 \mathrm{X}$. 


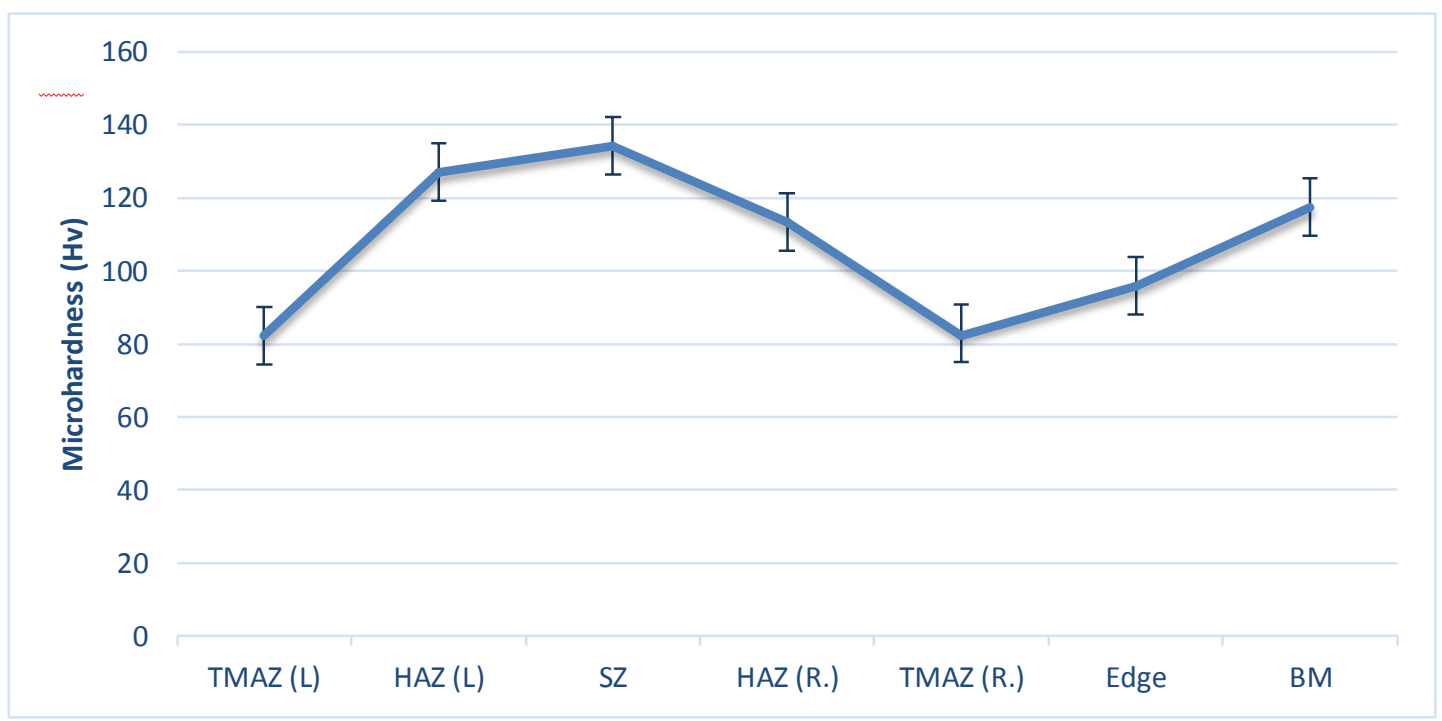

Fig. 10 Averages microhardness measurements of the different welding zones for $6061 \mathrm{Al}$ alloy.

\subsection{Vicker's Microhardness}

Microhardness investigation across the different zones of FSSW 6061 Al alloy is shown in Fig. 10. Vickers microhardness test was performed across the welded joint within each zone. Three readings were taken at each zone and the average of these readings was plotted as shown in Fig. 10. The microhardness value of the BM was found to be around $117 \mathrm{Hv}$, which is comparable to the microhardness values found in the literature of this alloy (about $107 \mathrm{Hv}$ ). The term "edge" as shown in Fig. 10 refers to the edge of the welded joint where the separation between the two plates is visible by means of optical microscopy. The microhardness value at this location was about $96 \mathrm{Hv}$. The microhardness within the TMAZ was the lowest value recorded for this welded joint, it was about 83 $\mathrm{Hv}$ and it was almost equal for both sides of the welded joint as shown in Fig. 10. Within the HAZ, the microhardness value was about $113 \mathrm{Hv}$ on the right side of the weld and about $127 \mathrm{Hv}$ on the left side of the welded joint. The interesting result was within the stir zone, the microhardness value within this zone was found to be about $134 \mathrm{Hv}$. This value is higher than the microhardness value for the $\mathrm{BM}$ and the highest microhardness value obtained across the welded joint. These microhardness results are in a good agreement with the $\mathrm{OM}$ and SEM micrographs of the different zones investigated in this study. According to the results stated above, the lowest microhardness value was revealed at TMAZ, while the SZ (welded metal) showed maximum microhardness. The high microhardness value of the SZ could be explained by considering the microstructure within this zone. Referring back to Fig. 7 that shows SEM of the SZ, the micrograph reveals fine equiaxed grain structure and thus the highest microhardness value. The microhardness within the HAZ was lower than that of the SZ but still higher than the microhardness of the BM. This can be explained through the Figs. 8 and 9 shown earlier. Those figures showed SEM micrographs within the HAZ, the grains within this zone did not change in size as compared to the grains within the SZ, but there was some structural modifications and new structure being developed. This is evident by the nucleation shown as many tiny white dots. The difference in microhardness and microstructure within the SZ and HAZ is explained by the fact that HAZ receives less heat from friction, hence undergoes some structural modifications and no plastic deformation occurs. The result of this difference is the large coarse grains.

The TMAZ microhardness was the lowest value within the welded region, even less than the hardness of the BM. The optical microscopy micrographs did not show any visible difference between these two regions. Within the TMAZ, the amount of heat generated by friction is expected to be much less than the SZ and HAZ but also sufficient to cause some structural modifications and some degree of plasticity in the material. Usually, the grains within the TMAZ as compared to the HAZ are elongated and more deformed. 
However, the SEM micrographs in terms of grain structure seem to be the same across the BM, TMAZ and HAZ with the exception of the nucleation event in the HAZ. In addition, the amount of heat generated within the TMAZ was not sufficient to allow the material to recrystallize and decreases the microhardness value.

\section{Conclusion}

Solid-state joining methods such as friction stir welding and friction stir spot welding are being widely used in many industrial applications due to their advantages over conventional joining and welding techniques. This work investigated the microstructural properties of $\mathrm{Al} 6061$ joints welded by FSSW. The optimum process parameters for joining Al6061 sheets by FSSW were identified in previous work and these optimum parameters were validated in the current work by means of microstructural investigation of the welding crosssections. The following conclusions can be outlined:

- Macrograph of the welding cross-section revealed that absence of the hook, which is a common defect in this type of welding.

- $\quad$ SEM micrographs of the HAZ showed grains nucleation and recrystallization; evidence of a higher thermal cycle as compared to the other regions.

- SEM micrograph of the SZ showed distinct difference as compared to the other regions in terms of grain structure.

- The microhardness values within the welded joint showed that the SZ had a microhardness value higher than that of the $\mathrm{BM}$, suggesting that failure will not occur within the welded area.

- Microstructure properties and microhardness measurements support the idea that these joints were fabricated under optimal process parameters and joint failure is not likely to occur within the welded joint.

\section{References}

[1] Iwamoto, R. Qiu, C., and Satonaka, S., (2009), "Interfacial microstructure and strength of steel/aluminum alloy joints welded by resistance spot welding with cover plate",
Journal of Materials Processing Technology, vol. 209, no. 8, 4186-4193.

[2] Zhengwei, Li., Gao., S., S. Ji, Y. Yue, and Chai, P., (2016), "Effect of rotational speed on microstructure and mechanical properties of refill friction stir spot welded 2024Al alloy", Journal of Materials Engineering and Performance, vol. 25, no. 4, 1673-1682.

[3] Thomas, W. M., E.D., Nicholas, J.C., Murch, M.G., Temple, S.P. and Dawes, C.J. , (1995) "Friction welding," Patent.

[4] Gerlich,,A., Su, P., and North, T. H.,(2005), "Tool penetration during friction stir spot welding of $\mathrm{Al}$ and $\mathrm{Mg}$ alloys", J Mater Sci, vol. 40, no. 24, 6473-6481.

[5] Chen, Y. C., Komazaki, T., Kim, Y. G., Tsumura,T., and Nakata, K., (2008), "Interface microstructure study of friction stir lap joint of $\mathrm{AC} 4 \mathrm{C}$ cast aluminum alloy and zinc-coated steel", vol. 111, no. 2-3, 375-380.

[6] Lin, P.-C., Pan, J., and Pan, T., (2008), "Failure modes and fatigue life estimations of spot friction welds in lap-shear specimens of aluminum 6111-T4 sheets, Part 1: Welds made by a concave tool", International Journal of Fatigue, vol. 30, 74-89.

[7] Tashkandi, M. A., Al-jarrah, J. A., and Ibrahim, M., (2017), "Spot welding of 6061 aluminum alloy by friction stir spot welding process", Engineering, vol. 7, no. 3, 16291632.

[8] Tashkandi, M. A., (2017), "Identifying and studying the impact of significant process parameters on friction stir spot welding of Al6061 using DOE", Journal of the North for Basic and Applied Sciences, vol. 2, no. 2, 125134.

[9] Effertz, P. S., (2015) "Friction stir spot welding of 7050-T76 aluminum alloy", Tecnico Lisboa.

[10] Chen, Y., (2015), "Refill friction stir spot welding of dissimilar alloys", University of Waterloo.

[11] Yang, X. W., Fu, T., and Li, W. Y., (2014), "Friction stir spot welding: A review on joint macro-and microstructure, property, and process modeling", Advances in Material Science and Engineering, vol. 2014, 1-11. 